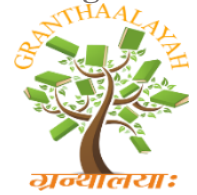

INTERNATIONAL JOURNAL OF RESEARCH GRANTHAALAYAH A knowledge Repository

\title{
DIGITAL ART: A REVOLUTIONARY FORM OF ART \& VISUAL COMMUNICATION
}

\author{
Dr. Anshu Srivastava *1 \\ ${ }^{* 1}$ Assistant Professor
}

\begin{abstract}
In this age of technology our life revolves around 2D; 3D images \& graphics. Creativity has now crossed all the limits it can't be restricted to brush and canvas. With the advent of various innovative software's designing is on the bloom and art become flawless. Digital art is harmony with good knowledge of design software enables us enter into the digital media industry. Today when everything around us become digitalized, the art are taking this step toward the digital world as well. The digital art is a most accepted form of art in the contemporary Indian art. This revolutionary form of art has given a new dimension of art, painting, sculpture and communication. Digital art is created by artist with the help of the computer and sometime modified by computer software. It also creates a subtle difference between design and art. Digital art is the outcome of creativity and computer technology.
\end{abstract}

Keywords: Digital Art; Revolutionary; Art \& Visual.

Cite This Article: Dr. Anshu Srivastava. (2019). "DIGITAL ART: A REVOLUTIONARY FORM OF ART \& VISUAL COMMUNICATION." International Journal of Research Granthaalayah, 7(11SE), 83-88. https://doi.org/10.29121/granthaalayah.v7.i11.2019.3705.

\section{Introduction}

Digital art is also called computer art and multimedia art. Digital art is known as new media art. It is a contemporary art that uses the methods of mass production or digital media. The technology of digital art is used extensively by the main stream media in advertising, and film makers to produce visual effects. Our society is becoming more and more dependent on graphic to communicate. We have no other choice then to bombard with images and visual messages. The product we buy the book and magazine we read, the computer games we play, the mobile, the computer, the Internet, all provides us an art that communicate through visual or images. Wherever, we go these forms of art and design comes with us in different mode as sign and symbol, icons, mobile and computer, on poster, hoarding and banner video games, animated videos etc. These all gives us an environment of communication. 


\section{Digital art an Introduction}

All the art work made with the help digital technology or presented on digital technology is digital art. In other words the art that completely done on computer or sometime scanned and finished using software program is said digital art. The term 'digital art' was first used in 1980's in connection to an early computer painting program. It is a method of art making that lend itself to a multimedia format because it can potentially be viewed in many ways as on TV, computer, mobile, internet and on multiple social media platform. In short digital art is sort of merge between art and technology, that allow many new ways to create artwork.

Digital art is like any other art. It is created using a computer rather than the more traditional art tool. Today art has crossed all boundaries and shifted from canvas to the TV, computer, and mobile screen. it is quickly becoming a reputable form of art in our society. It is derived from the concept of traditional art forms but has the components of new technology. The advancement in digital technology allows the artist to create an art work that can now be seen and appreciated all over the world. Digital art has not only expanded the defining of art but has increased the accessibilities of art to the world.

Now art is not only meant for a piece of decoration or it is not about the tools used to create it, rather then it is a form of communication, it is a medium to convey messages, or emotion of the artist or designer. Just like photography is a medium through which artist may create art, likewise a computer is just a medium or tool through which an artist can express his/her vision of line, form, color, composition and rhythm. Artists expand their creative boundaries with the use of technology. They use specific software to create their works. The benchmark for such software is a realistic painting experience, in which you can choose the method and brush. Some software like Coral Draw, Photoshop, Autodesk sketch book are popular among artist they provide a wide variety of creative option.

\section{Classification of Digital art}

Digital art can be classified in two broad categories by Art Historian as 'object-oriented art work' and 'process-oriented visuals'. First category is as digital technology function as a tool for creation of traditional object like painting, photographs, prints, and sculptures. The second category associated with the term "New Media" it refers to all computable art that is digitally created, stored and distributed. It can also be said that some digital work depends on digital tools to expand an already existing medium, others use digital technology as a fundamental and in dissociable component in the making of the artifact.

\section{Digital Painting}

Creating any art work digitally on a computer through software that uses brushes much like traditional painting is digital painting. In 1990's Digital painting come in light with traditional painting techniques like water colors, oil paintings, and impastos. The artist began to create a graphical design with the use of a computer; tablet or stiletto, the process itself is similar to painting with traditional, materials. With the use of painting tool 2D images created in virtual environment. The artist uses 3D modeling and rendering software to essentially sculpt in virtual space. Artist 
focuses more on illustration work and developing their own style. Some work in entertainment industry they create digital production art like concept art or animation. Concept artist can also merge photo or 3D models into their 2D paintings it is called photo bashing digital art is pinnacle of modern art.
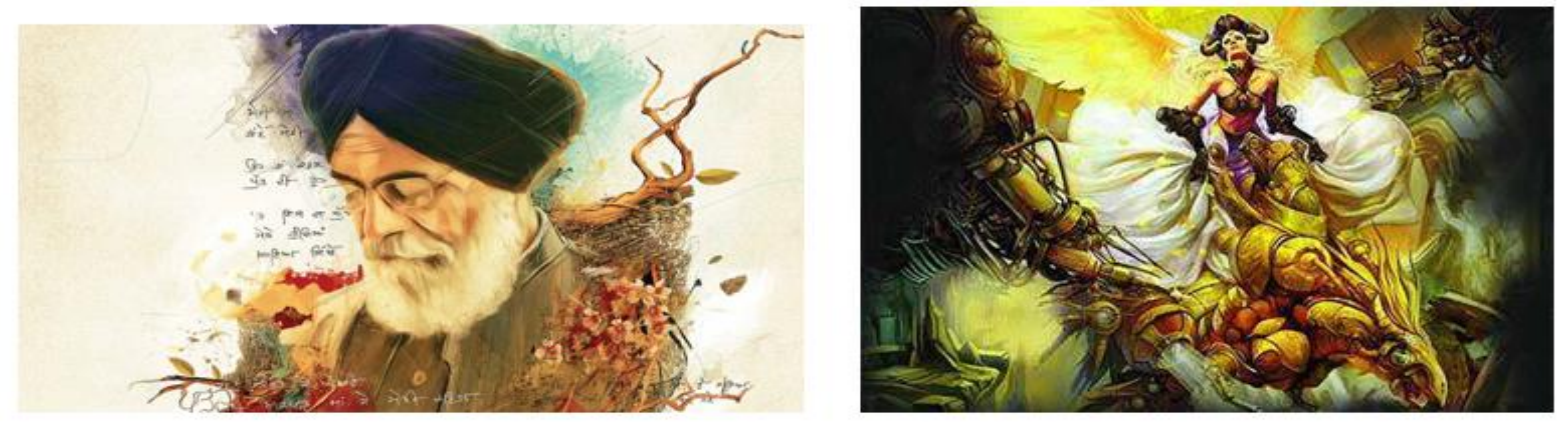

\section{Digital Photography}

Digital photography is a form of art that has become incredibly popular over the last few decades. Artist uses a digital or conventional camera. Digital cameras allow photographers to quickly snap, edit, and share. There are hundreds of types of digital cameras, editing software, and so much more to choose from. The photographs are digitized and translated to the computer environment where the artist uses image editing and special effects software to perform darkroom type manipulations.

\section{Digital Graphic}

A graphic is an image or visual representation of an object. Digital graphic are simply images created on computer to communicate any kind of messages. It is the art of combining text and pictures to communicate the message in advertisement books, newspapers and magazines. It is a skill and an essential part of visual communication. It is in a form of painting that is created by the help of computer application to communicate the information and message. It is a form of drawing and painting interweave with communication.
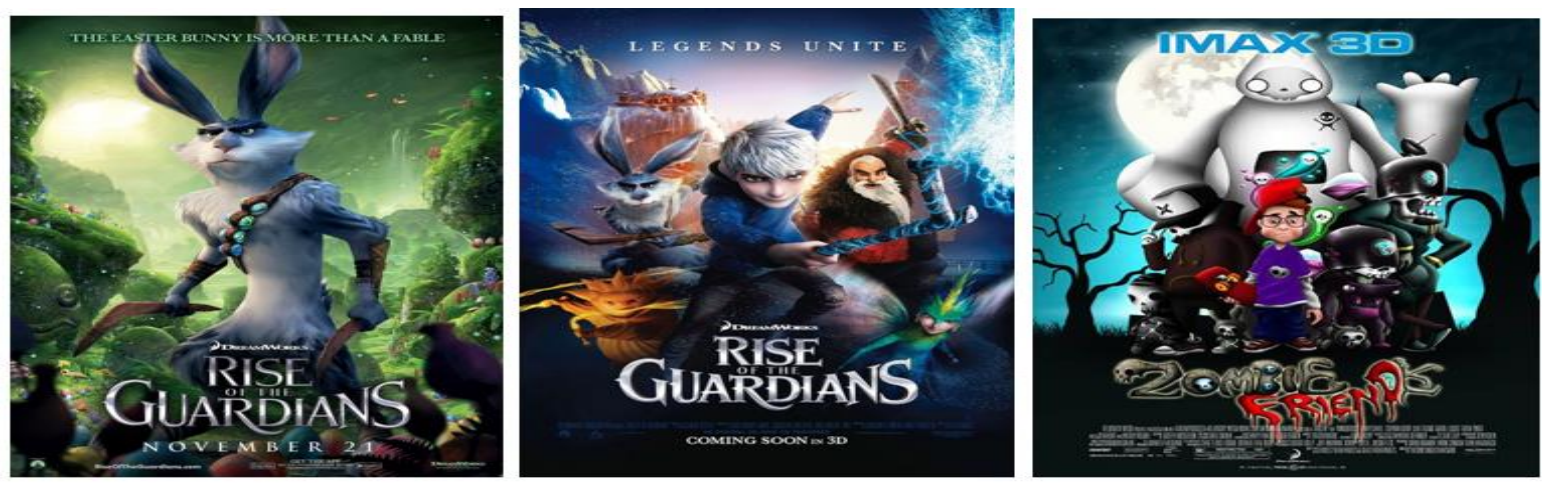

\section{Digital Installation}

The term installation is derived from a Latin word 'in-stallo' which means, placing something in affixed and frozen position, where nothing can be changed. When this process is done through the 
help of computer application it is called digital installation. This art form has used in broad range of contemporary art's practice which include2D and 3D materials to help to get experience or observation of a particular space. Where the objects and space remains alive in the artwork. The contemporary artists are getting motivation from film and television, for making environment that permits viewer to experience different spaces and concurrent occasions, with the assistance of sound, story and picture.
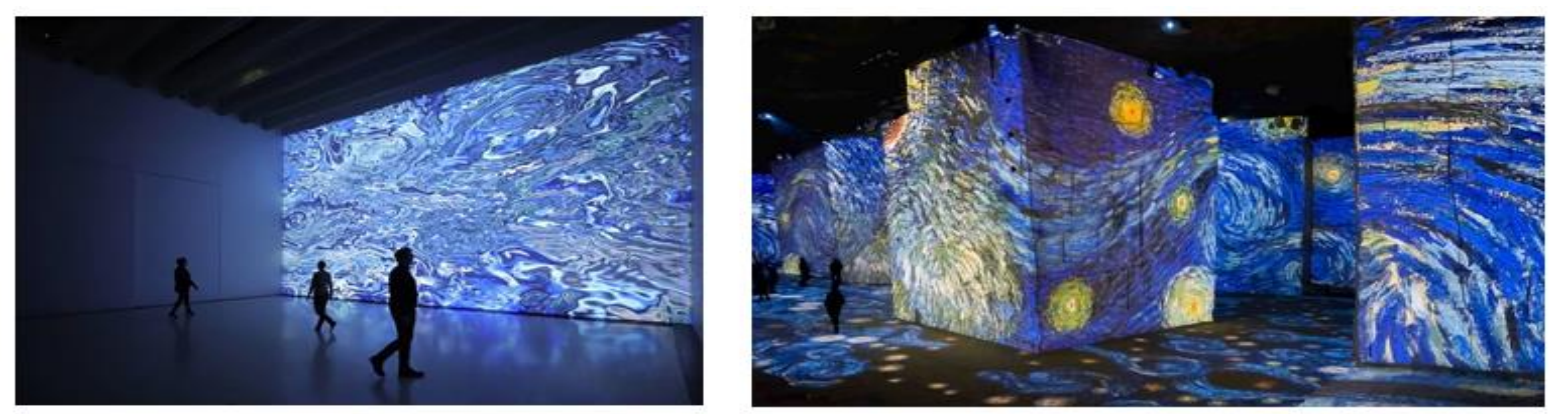

\section{Digital Animation}

The term animation derived from a Latin word 'anima' meaning 'soul'. It is a process of art in which an artist can display a sequence of images to create the visual illusion of motion and living objects. Digital animation is a process in which artist can create moving images by the use of computers and animation software such as adobe flash, light wave, Dream studio and many more. It includes a method used to create animated images through computer graphics.
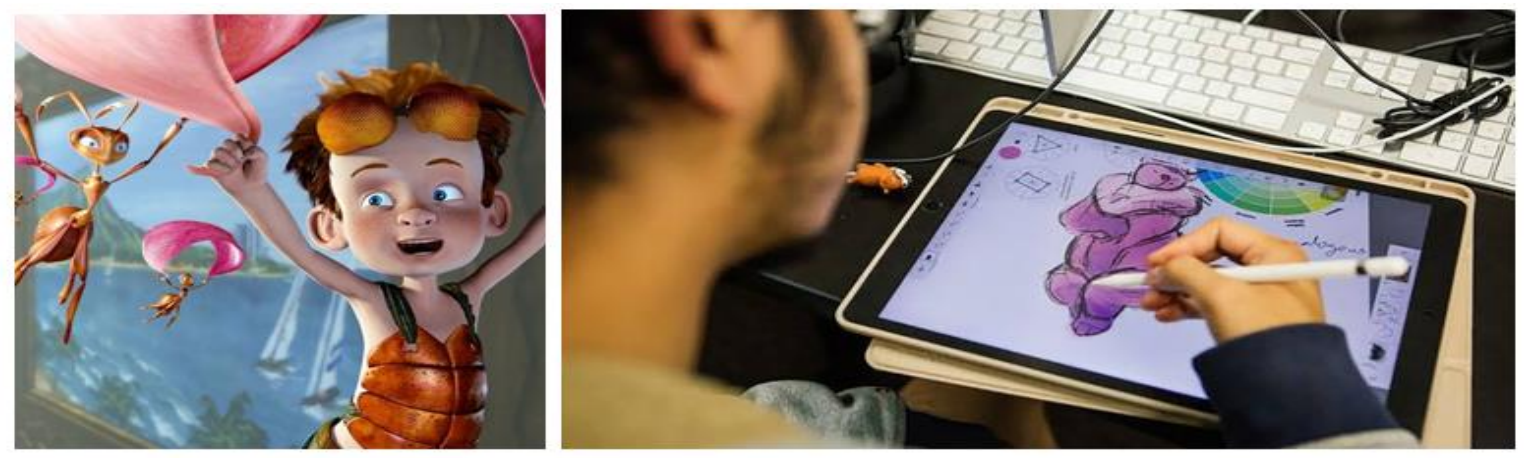

\section{Evolution of Digital art and Graphic design}

Visual presentation that performed with the help of computer and the image results on computer screen then it is called digital graphics. It incorporates drawing painting photographs, printmaking typography serigraphy, two dimensional and three-dimensional art forms. The communication through drawing began with the walls of caves, where early people use to draw their thought and feeling to give message and information. Later in the medieval times, various manuscripts and miniature paintings were physically replicated copies with individual page of the original copies were utilized to keep up their sacred teaching.

With the invention of printing press a great change came in 1440. The mass production of text and graphic art began and replaced manual transcriptions. Then during the industrial revolution the 
development of large fonts as poster became were used to give the latest information to advertising the products and services. The invention and popularity of television has entirely changed the world of graphic art. With the development of computer in twentieth century graphic art changed completely. Various computer software programming developed that empowers artists to control picture in a much faster and easier way and with fast calculations. Computers effectively recolor, scale, rotate and rearrange the images. The term digital graphic art or digital art has become very widespread today. The digital art and graphic denote to several distinctive things like representation and control of picture \& information by computer. Digital graphics are used in various area and it leave with a profound effect on numerous services of media and have reformed animation education and film making into most advanced industries of present era.

The expression digital graphic was invented in 1960 by William Fetter a graphic designer at Boeing. Many organizations established in the field of digital art and graphics during the mid 1960s. IBM came speedily with the IBM 2250 graphics terminal, the first commercially available graphic computer in the world. 3D graphics representation became more popular in 1990s in games, entertainment, interactive media and animation industry. The $21^{\text {st }}$ century advance software programming for digital art and graphic developed which picking up further heights. Today there are rapid developments in technology changing our social interactions and the visual landscape through Digital Art. Artists are encouraged to reflect, discover and invent new artistic expressions based on what has already been discovered by master artists. The new evolution allows artist to play with media and develop new art forms. Digital and commercial art are an integral part of art movement.

\section{Digital Art Intersection with Graphic Design and Visual Communication}

Digital art and graphic design both encompass media development discipline, both the two fields set out to create forms of visual communication media that often relate an idea, image or brand to an audience. Visual communication is the communication of ideas the visual display of information primarily associated with two dimensional images, it include art, sign, photographs, drawing fundamentals, color and electronic resources like motion picture animation videos etc.

Graphic design means design appear on marketing material like print advertising, poster or billboards, brochures, magazines, consumer product and clothing. Digital art or Digital media designs are motion graphics, screen writing and video editing, digital audio production and video production. Digital media designer creates their products in digital as electronic format as opposed to graphic designer who apply graphic imaging to both digital and tangible platforms.

\section{Conclusion}

Technology has had a major impact on the arts. Contemporary art has been greatly influenced by the rapid development in digital technology. Digital art is a technology as an essential part of the creative or presentation process. It is also called computer art and multimedia art. Digital art is also known as part of a new media art. It is contemporary art that uses the methods of mass productions or digital media. The techniques of digital art are used extensively by the mainstream media in advertisement, film makers to produce visual effects. 
A graphic designer is a communicator first, artist second and a digital artist is an artist first a communicator second. In other words graphic designer is a visual problem solver their job is to creatively solve various communication challenges via the combination of typography, graphic, imagery, and in some field sound like motion and web designer facilitating a visual conversation between a business and their consumers. Graphic designers are web designer, print designer packaging designer motion graphic designer etc. Digital artist is someone that creates art via digital media. The term digital artist covers a very wide range of people and is less a title than a description of how they achieve what they are doing. Digital artist is concept artist, matte painters, story boarding artist 3D artist, and some of them are fine art like Painting and digital illustrator.

Digital art and graphic design both are the member of the same family. Both the two fields set out to create forms of visual communication media that often relate an idea, image or brand to an audience. Digital art and graphic design both are created to communicate some visual messages either in the form of advertisement or in the form of story boarding or digital painting. Both two fields are different in many ways the biggest difference is in what they communicate, not how they achieve it. The part that makes the distinction difficult is that the two fields often intersect. Digital art and graphic design both are birds of a feather flock together.

\section{References}

[1] Digital Art- The style of modern times. http://www. Creativegaga.com/

[2] Digital art - A revolutionary form of art. http:// www. feltmagnet.com/

[3] Graphic design form India will shine a light on independent talent from the sub continent http://www.itsnicethat.com/

[4] What is digital art? Jeri Holt http/ www.withdigitaleyes.com

[5] 20 best Indian Digital Artists to be inspired from! http:/ www.creativegaga.com

[6] Caplin, Steve and Banks, Adam (2003). The Complete Guide to Digital Illustration. Publisher: Alastair Campbell

[7] Dr. Farha Abrar, 'Use of digital art in contemporary Indian Era' shodhganga.inflibnet.ac.in>bitstream

[8] Digital art rules! http//www.m.timesofindia.com

[9] What is digital art? Definition and scope of the New media http://www.medium.com 